\title{
Breastfeeding-Friendly Primary Care Initiative: Degree of implementation in a Brazilian metropolis ${ }^{1}$
}

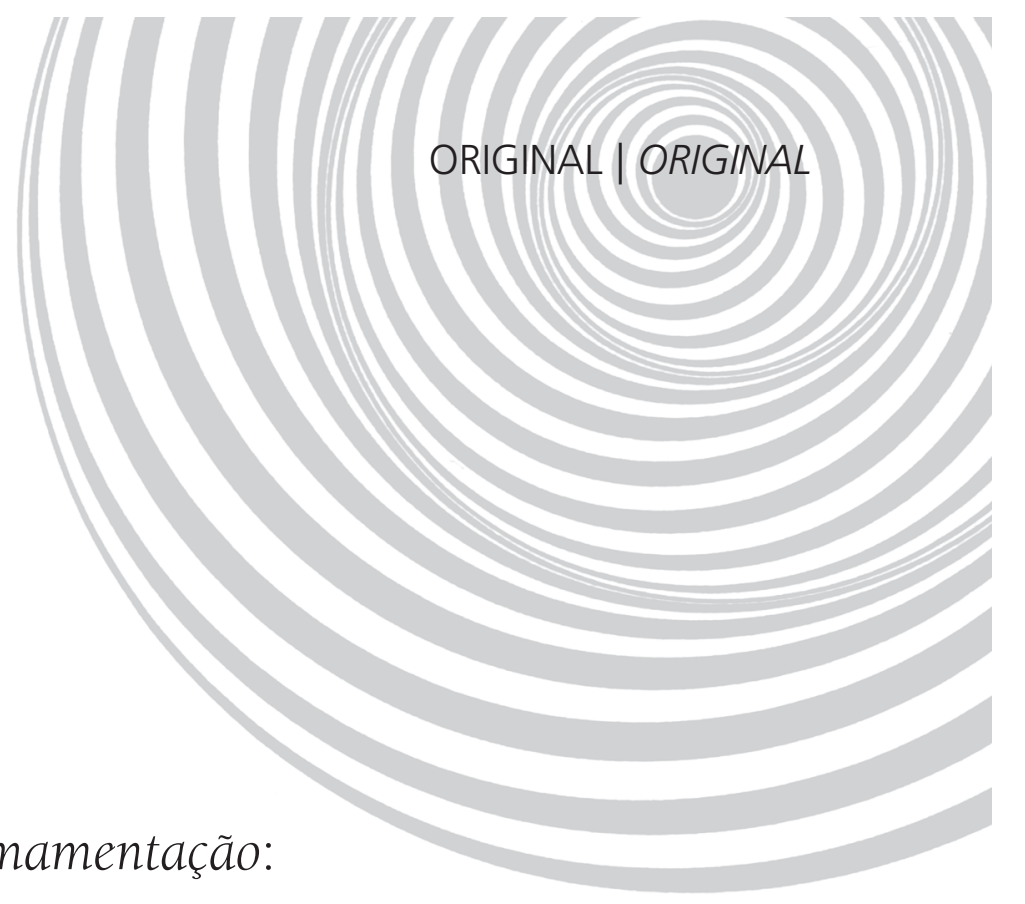

\author{
Iniciativa Unidade Básica Amiga da Amamentação: \\ avaliação do nivel de sua implantação \\ em uma metrópole brasileira
}

Rosane Valéria Viana Fonseca RITO2 Inês Rugani Ribeiro de CASTRO ${ }^{3}$ Alexandre José Baptista TRAJANO ${ }^{4}$

Maria Auxiliadora de Souza Mendes GOMES 5

Regina Tomie Ivata BERNAL ${ }^{6}$

A B S T R A C T

\section{Objective}

This study assessed the degree of implementation of the Breastfeeding-Friendly Primary Care Initiative in a Brazilian metropolis.

\section{Methods}

A tool with 55 items and a maximum score of 10 points, based on validated protocols, was developed for assessing the degree of implementation of the abovementioned initiative. This tool was used on a probabilistic sample of municipal primary care units in the city of Rio de Janeiro, Brazil $(n=56)$. Managers $(n=56)$, healthcare practitioners $(n=541)$ and users $(n=985)$ were interviewed.

\section{Results}

The mean score for the degree of implementation of the Breastfeeding-Friendly Primary Care Initiative in the study units was $5.45(95 \% \mathrm{Cl}: 5.11$ - 5.78), the maximum being 10.00. Existence of written guidelines and training obtained the worst scores. Breast massage and manual milk expression techniques; knowledge about

1 Article based on the thesis of RVVF RITO, intitled "Iniciativa Unidade Básica Amiga da Amamentação: avaliação da implantação em unidades da rede básica de saúde da cidade do Rio de Janeiro". Fundação Oswaldo Cruz; 2009.

2 Universidade Federal Fluminense, Faculdade de Nutrição. R. São Paulo, 30, Sala 407, Campus Valonguinho, Centro,

24020-150, Niterói, RJ, Brasil. Correspondência para/Correspondence to: RVVF RITO. E-mail: <rosane.rito@gmail.com>

${ }^{3}$ Universidade do Estado do Rio de Janeiro, Instituto de Nutrição. Rio de Janeiro, RJ, Brasil.

${ }^{4}$ Universidade do Estado do Rio de Janeiro, Faculdade de Medicina. Rio de Janeiro, RJ, Brasil.

${ }^{5}$ Fundação Oswaldo Cruz, Instituto Fernandes Figueira. Rio de Janeiro, RJ, Brasil.

${ }^{6}$ Universidade de São Paulo, Faculdade de Saúde Pública. São Paulo, SP, Brasil. 
386 | RVVF RITO et al.

contraception and the risks associated with the use of baby formulas, bottles, and pacifiers; and existence of support groups obtained intermediate scores. Provision of information and recommendations on breastfeeding rights and advantages; addressing users' worries, life experiences, and doubts; and encouraging cue feeding achieved the best scores.

\section{Conclusion}

The proposed tool assessed the general degree of implementation of the Breastfeeding-Friendly Primary Care Initiative and of each group of actions associated with the "Ten Steps", providing information for restructuring the strategies used in Rio de Janeiro. The degree of implementation of breastfeeding promotion, protection, and support set by the initiative in this city is intermediate, with its items having been implemented to different degrees.

Indexing terms: Breastfeeding. Breastfeeding-Friendly Primary Care Initiative. Primary healthcare.

\section{R E S U M O}

\section{Objetivo}

Avaliar o nível de implantação da Iniciativa Unidade Básica Amiga da Amamentação em uma metrópole brasileira.

\section{Métodos}

Com base em protocolos validados, criou-se ferramenta de avaliação do nível de implantação composta por 55 parâmetros, gerando escore final que poderia variar de 0 a 10 pontos. Aplicou-se essa ferramenta em amostra probabilística das unidades básicas municipais de saúde da cidade do Rio de Janeiro $(n=56)$. Foram entrevistados gestores $(n=56)$, profissionais de saúde $(n=541)$ e usuárias $(n=985)$.

\section{Resultados}

A média do escore final das unidades básicas municipais de saúde referente ao nível de implantação da Iniciativa Unidade Básica Amiga da Amamentação foi de 5,45 (IC95\%: 5,11 - 5,78). Observaram-se piores resultados em relação à norma escrita e ao treinamento. As técnicas de massagem e de ordenha das mamas, conhecimentos sobre contracepção, riscos do uso de fórmulas infantis, mamadeiras e chupetas e a implantação de grupos de apoio apresentaram resultados intermediários. As orientações sobre direitos, vantagens e recomendações relativas à amamentação, a escuta das preocupações, vivências e dúvidas da clientela e o encorajamento da amamentação sob livre demanda tiveram resultados mais satisfatórios.

\section{Conclusão}

A ferramenta desenvolvida permitiu a avaliação do nível geral de implantação da Iniciativa Unidade Básica Amiga da Amamentação e de cada conjunto de ações correspondentes aos "Dez Passos", fornecendo subsídios para reorientação das estratégias utilizadas na cidade. A cidade do Rio de Janeiro apresenta nível intermediário de implantação das ações de promoção, proteção e apoio à amamentação, preconizadas pela Iniciativa e pela heterogeneidade na implantação das atividades que a compõem.

Termos de indexação: Aleitamento materno. Iniciativa Unidade Básica Amiga da Amamentação. Atenção primária à saúde.

\section{INTRODUCTION}

Rated as one of the main actions fostering food safety ${ }^{1}$, breastfeeding has been described as the best contributor to children's growth and development ${ }^{2,3}$, and also benefits the mother's health ${ }^{4,5}$. Despite its importance and the fact that 99.5\% of Brazilian children begin breastfeeding on the first day of life, early weaning rates are still high in Brazil6.
Since the beginning of the 1980s, investments have been allocated to a nationwide policy designed to restore this practice on a wider scale by linking and mobilizing various segments of the Brazilian society ${ }^{7-9}$. In the state of Rio de Janeiro, the implementation of the BreastfeedingFriendly Primary Care Initiative (BFPCI) began in 1999. This initiative, inspired by the Baby-Friendly Hospital Initiative (BFHI), was designed to 
promote, protect and support breastfeeding at the primary healthcare level ${ }^{10}$.

The BFPCl is based on the "Ten Steps for Successful Breastfeeding in Primary Care", which in turn is based on the assumption that prenatal care, childcare, and pediatrics provide a valuable opportunity for developing health-promoting activities and preventing and solving problems that may lead to early weaning. For this purpose, practitioner training is highly prioritized so that practitioners may implement standard and consistent actions based on scientific knowledge, actions that extend beyond the boundaries of biology and encompasses every aspect of lactating mothers ${ }^{11,12}$.

The process of qualifying primary care units for the $\mathrm{BFPCI}$ was regulated in $2005^{13}$. This process requires that two external experts assess the $\mathrm{BFPCI}$ activities performed by a primary care unit. This assessment uses tested and validated protocols for analyzing documents from the prenatal and pediatric care services and includes interviews with unit managers, healthcare practitioners, pregnant women, and mothers of infants under one year of age. Ten sets of items are used for assessing compliance with the Ten Steps. The units are considered compliant with a step if at least $80 \%$ of its items are in effect. The title of Breastfeeding-Friendly Primary Healthcare Unit (BFPHU) is awarded for units that comply with all Ten Steps.

The Municipal Department of Health of Rio de Janeiro (SMS-RJ) started implementing the $\mathrm{BFPCl}$ in its primary healthcare units in 2000. Between 2003 and 2006, 69 courses were provided, qualifying more than 1,700 healthcare practitioners and community health agents. Seven years later, in 2007, the number of units awarded the BFPHU title became an indicator of the degree of $\mathrm{BFPCI}$ implementation in Rio de Janeiro because no tool was available to make a more thorough analysis. However, the number of units awarded this title (five) did not seem to fairly reflect the efforts made by the SMS-RJ to implement this initiative or the progress made by primary healthcare units, evident during supervised activities. Seeking to overcome this gap and contribute to the advance of knowledge in this field, this study assessed the level of BFPCI implementation in the city of Rio de Janeiro.

\section{METHODS}

\section{Instruments and criteria used for assessing the degree of $\mathrm{BFPCl}$ implementation}

The tools used for assessing the degree of $\mathrm{BFPCl}$ implementation were the ten protocols used for awarding the BFPHU titles to the units, validated for this purpose ${ }^{12}$. These protocols included document analysis, observation of prenatal and pediatric services, and interviews with primary care staff and users. In each primary care unit, a manager, ten healthcare practitioners, ten pregnant women, and ten mothers of infants under a year of age were interviewed.

These protocols were based on the "Ten Steps for Successful Breastfeeding in Primary Care". They encompass structural aspects and written guidelines and routines (Step 1); professional training (Step 2); guidance on the duration of exclusive and non-exclusive breastfeeding, related advantages and legal rights (Step 3); boosting breastfeeding confidence (Step 4); breastfeeding lessons in the maternity hospital clinic (Step 5); suitable contraception while breastfeeding (Step 7); risks associated with using baby formulas and artificial nipples (Step 9); practical advice on latch on and position hand expression, and breastfeeding on demand (Steps 6 and 8); and organizing support groups and/or home visits (Step 10).

This study adapted the assessment criteria used for awarding the BFPHU title to identify the degree of $\mathrm{BFPCl}$ implementation. This means that instead of indicating no or full implementation, the results show the degree of implementation, which may vary from 0 to 10 points, the latter being full implementation. 
The degree of $\mathrm{BFPCl}$ implementation reflects a unit's compliance with 55 items grouped into ten sets of activities that promote, protect, and support breastfeeding in primary care. Each set reflects each of the Ten BFPCI steps (set 1 reflects step 1 and so on). Each set is given a score from 0 to 1 . The number of items in each set varied from three (Sets 4, 5, 6, and 8) to 11 (Set 3). Consequently, for these sets to be equivalent to the BFPCI steps, that is, for each set to contribute equally to the final score of a primary care unit, each set could have a maximum score of 1 point, and this point would be divided by the number of items in the set. For example, since set 1 consisted of 5 items, each item was worth 0.2 points. The final score, which varied from 0 to 10 points, was given by adding the scores of the ten sets.

Scores for items that required interviews were given by the number of completed interviews. Thus, all the study items were scored, even if, for example, not all practitioners of a unit were fully interviewed.

Chart 1 summarizes the 55 items grouped into ten sets and the associated maximum score. Different items in a set may rely on different sources for its data. For example, the items in set 9 rely on direct observation or interviews with managers, practitioners, pregnant women, and mothers.

\section{Sampling}

A probabilistic sample of the primary care network was implicitly stratified by regions, called planning areas, and the units within were classified according to the healthcare model they used and their size, resulting in three categories: traditional large (>162 visits), traditional small (<=162 visits) and Family Health Clinics/ Community Health Agents Program (FHP/CHAP).

The unit records of 2007 were used for unit selection. The median monthly number of prenatal visits held at these units during the first half of 2007 was used for sizing the traditional units (small and large). At that time there were 152 units: 79 traditional primary care units (38 large and 41 small) and 73 FHP or CHAP.

The final sample should consist of 56 primary care units, but an oversample of $3 \%$ was used to cover possible losses, totaling 58 units. This size was large enough to estimate the mean variable of interest (final score) with a maximum acceptable error of $5 \%$ at a confidence level of $95 \%$, assuming that the center of the proposed scale (5) would be the expected (mean) value of the score and 1.2 would be the standard deviation of this mean, as these values were not known beforehand ${ }^{14}$.

The expansion factors for the sample corresponded to the inverse probability of including the units in the strata to which they were allocated.

\section{Data collection and analysis}

The units were assessed by two BFPCI experts trained by the State Department of Health and Civil Defense of Rio de Janeiro (SESDEC-RJ, Rio de Janeiro) who were, at that time, part of the staff of experts in charge of the accreditation processes. These experts were always from outside the planning area of the selected unit. Unit managers, healthcare practitioners, pregnant women, and mothers of infants under one year of age were interviewed. A specific questionnaire was used for each group (assessment protocols for BFPHU title awards, as detailed above).

Data were collected from November 2007 to May 2008 after meetings with representatives of the planning areas and selected units to inform them of the assessment process. The units were visited up to three times to complete the required number of interviews.

The general degree of $\mathrm{BFPCI}$ implementation and implementation of the sets related to the Ten Steps in the municipality of Rio de Janeiro were respectively estimated by the mean final score and 
Chart 1. Assessment criteria for the degree of implementation of the Breastfeeding-Friendly Primary Care Initiative: items and their respective scores.

Continuation

\begin{tabular}{llc}
\hline Set & Item & $\begin{array}{c}\text { Score assigned } \\
\text { to each item }\end{array}$ \\
\hline
\end{tabular}

1 1. Have written breastfeeding guidelines and routines.

2. Provide a copy of these guidelines for assessment.

3. Number of $\mathrm{BFPCl}$ steps addressed by the guidelines.

4. Display the guidelines in at least two common areas frequented by pregnant women and mothers with babies.

5. Guidelines and routines are easy to understand by staff and users.

1. The healthcare staff has been advised on the breastfeeding standards according to the primary care unit manager.

2. Evidence of staff training in the mother-and-child sector.

3. The staff in the mother-and-child sector has a copy of the breastfeeding training program.

4. The training consists of at least 20 hours of lecture.

5. The training consists of at least 3 hours of supervised clinical practice.

6. Number of $\mathrm{BFPCI}$ steps encompassed by the training syllabus.

7. Proportion of trained practitioners working in the mother-and-child sector.

8. Proportion of practitioners who have worked in the mother-and-child sector for less than six months and still require training.

9. Proportion of randomly selected staff that has already been duly trained.

10. Proportion of interviewed practitioners who answered correctly at least 13 of the 15 specific questions on breastfeeding management and guidance.

1. Existence of breastfeeding groups according to the unit heads.

32 2. Report presented by the unit head with a minimum amount of educational activities at the prenatal and pediatric sectors.

3. Proportion of interviewed practitioners who knew about breastfeeding protection laws.

4. Proportion of interviewed practitioners who stated that babies should only be introduced to other fluids or foods after six months of age.

5. Proportion of interviewed practitioners who stated that babies must be breastfed for at least two years.

6. Proportion of interviewed pregnant women who knew two advantages of breastfeeding.

7. Proportion of interviewed pregnant women who had received counseling on exclusive or nonexclusive breastfeeding.

8. Proportion of interviewed mothers who had received counseling on exclusive breastfeeding.

9. Proportion of interviewed mothers whose child had not been prescribed any fluid or food before his sixth month of age except for medical reasons.

10. Proportion of interviewed mothers who had received counseling on nonexclusive breastfeeding for at least two years.

11. Proportion of interviewed mothers who were not given baby formula at the unit during the baby's first six months of life.

1. Proportion of interviewed practitioners who knew mothers' common breastfeeding concerns or doubts and who had provided care that effectively increased mothers' confidence.

2. Proportion of interviewed pregnant women who had received care and advice that increased their confidence.

3. Proportion of interviewed mothers who had received care and advice that increased their confidence.

1. Proportion of interviewed practitioners who stated that breastfeeding must begin within the first hour of birth.

2. Proportion of interviewed practitioners who mentioned at least two advantages of room sharing.

3. Proportion of interviewed pregnant women who had been informed of the importance of breastfeeding within the first hour after the birth and/or the importance of room sharing.

1. Proportion of interviewed practitioners who explained how to maintain lactation and manually express milk, demonstrating the correct position by gripping the areola.

2. Proportion of interviewed pregnant women who were taught how to maintain lactation; the correct position, latch on the areola and/or expressing milk manually.

3. Proportion of interviewed mothers who were taught how to maintain lactation; the correct position, latch on the areola and/or expressing milk manually. 
Chart 1. Assessment criteria for the degree of implementation of the Breastfeeding-Friendly Primary Care Initiative: items and their respective scores.

Conclusion

\begin{tabular}{|c|c|c|}
\hline Set & Item & $\begin{array}{c}\text { Score assigned } \\
\text { to each item }\end{array}$ \\
\hline 7 & $\begin{array}{l}\text { 1. Proportion of interviewed practitioners who knew about the lactational amenorrhea method and the } \\
\text { contraindications of exclusive breastfeeders taking the pill. } \\
\text { 2. Proportion of interviewed mothers who were informed about suitable contraceptive methods while } \\
\text { breastfeeding. }\end{array}$ & 0.5 \\
\hline 8 & $\begin{array}{l}\text { 1. Proportion of interviewed practitioners who knew that breastfeeding on demand is a must. } \\
\text { 2. Proportion of interviewed pregnant women who had been encouraged to breastfeed on demand } \\
\text { 3. Proportion of interviewed mothers who had been encouraged to breastfeed on demand. }\end{array}$ & 0.333 \\
\hline 9 & $\begin{array}{l}\text { 1. Users protected from the marketing of formulas and other baby foods, bottles, nipples, and pacifiers, } \\
\text { according to the unit heads. } \\
\text { 2. Proportion of interviewed practitioners who reported that the unit was not given samples of infant } \\
\text { formulas. } \\
\text { 3. Proportion of interviewed practitioners who knew that bottles pose a risk to breastfeeding. } \\
\text { 4. Proportion of interviewed practitioners who knew that pacifiers pose a risk to breastfeeding. } \\
\text { 5. Proportion of interviewed pregnant women who had been informed about the risk of using bottles or } \\
\text { pacifiers. } \\
\text { 6. Proportion of interviewed mothers who had been informed about the risk of using bottles or pacifiers. } \\
\text { 7. Experts found no advertising or distribution of baby formulas, bottles, nipples, or pacifiers, or any sample of } \\
\text { these products in the unit. } \\
\text { 8. Experts found no representatives or salesmen of the baby food or nipple industries at the unit. } \\
\text { 9. Experts found that the products found in the unit storage designed for pregnant women or babies were } \\
\text { medically appropriate, within their expiry dates, and compliant with the Brazilian Act on the Sale of Foods, } \\
\text { Nipples, Pacifiers, and Bottles for Breastfeeding Mothers and Young Babies. }\end{array}$ & 0.111 \\
\hline 10 & $\begin{array}{l}\text { 1. Unit head confirmed that pregnant women and mothers received breastfeeding advice in groups or during } \\
\text { home visits. } \\
\text { 2. Proportion of interviewed pregnant women who participated in group activities or were visited at home, } \\
\text { where they exchanged experiences and received breastfeeding advice. } \\
\text { 3. Proportion of interviewed mothers who participated in group activities organized by the unit or were } \\
\text { visited at home, where they exchanged experiences and received breastfeeding advice. } \\
\text { 4. Proportion of interviewed pregnant women with at least one family member who had been invited to } \\
\text { participate or was present at some activity (group, visit, home visit or other) organized by the unit that } \\
\text { included breastfeeding advice. } \\
\text { 5. Proportion of interviewed mothers with at least one family member who had been invited to participate or } \\
\text { was present at some activity (group, visit, home visit or other) organized by the unit that included } \\
\text { breastfeeding advice. } \\
\text { 6. Proportion of interviewed mothers who had been told to revisit the unit whenever they had a breastfeeding } \\
\text { problem to receive the necessary support without the need of appointments. }\end{array}$ & 0.166 \\
\hline
\end{tabular}

Note: PCU: Primary Care Unit; BFPCI: Breastfeeding-Friendly Primary Care Initiative.

the mean score of each of the ten sets of all the study units. The means and their respective 95\% confidence intervals $(95 \% \mathrm{Cl})$ were estimated with the sampling design in mind. The set scores are presented by a scatter box plot. The final scores by planning area and unit classification were compared by examining the $95 \% \mathrm{Cl}$ of the estimates. The differences were considered significant when the $\mathrm{Cl}$ of the compared groups did not overlap. To reduce the number of categories for each variable, the planning areas were regrouped into five regions by geographical proximity, and the units were regrouped by care model: traditional and family health strategy.

The data were entered in the EPI-DATA 3.4 software and the item scores, set scores, and 
final primary care unit scores were calculated by the software Statistical Package for the Social Sciences (SPSS), version 13.

This study is in compliance with Resolution $n^{\circ} 196 / 96$ issued by the National Health Council (CNS), which establishes the guidelines and regulations for research on human beings. The study was approved by the Research Ethics Committee of the Municipal Health Department and Civil Defense Force of Rio de Janeiro, under protocol number 158a/2007.

\section{RE S U L T S}

A total of 56 units were assessed, of which 16 were large traditional units, 12 were small traditional units, and 28 were FHP/CHAP units. Two initially sampled units were not studied: one of them (CHAP) was deactivated and the other (FHP) could not be visited because of safety reasons, despite several attempts. A total of 56 unit managers, 541 practitioners, 485 pregnant women, and 500 mothers were interviewed, $100.0 \%, 96.6 \%, 86.6 \%$, and $89.3 \%$ of the planned interviews, respectively.

The mean final score of the units for degree of $\mathrm{BFPCl}$ implementation in the municipality of Rio de Janeiro was 5.447 (95\% Cl:
5.111-5.784) (Table 1). Sets 1 and 2 had the worst scores: 0.258 and 0.403 , respectively; they regarded the provision and display of breastfeeding guidelines and routines, and the training of human resources.

The following five sets had average scores, varying from 0.479 to 0.632 : set 9 (risks associated with using baby formulas, feeding bottles and pacifiers); set 10 (breastfeeding support groups); set 6 (breastfeeding management techniques); set 7 (appropriate contraceptive methods while breastfeeding); and set 8 (encourages breastfeeding on demand).

Table 1. Mean scores of each set of Breastfeeding-Friendly Primary Care Initiative items and mean final scores of the study primary care units. Rio de Janeiro (RJ), Brazil, 2008.

\begin{tabular}{lll}
\hline Variables & Mean & 95\% confidence interval \\
\hline Sets & & \\
1 & 0.258 & $0.174-0.342$ \\
2 & 0.403 & $0.338-0.468$ \\
3 & 0.706 & $0.675-0.737$ \\
4 & 0.722 & $0.678-0.765$ \\
5 & 0.763 & $0.733-0.792$ \\
6 & 0.497 & $0.453-0.541$ \\
7 & 0.500 & $0.457-0.542$ \\
8 & 0.632 & $0.599-0.665$ \\
9 & 0.479 & $0.458-0.500$ \\
10 & 0.489 & $0.446-0.532$ \\
Final Score & 5.447 & $5.111-5.784$ \\
\hline
\end{tabular}

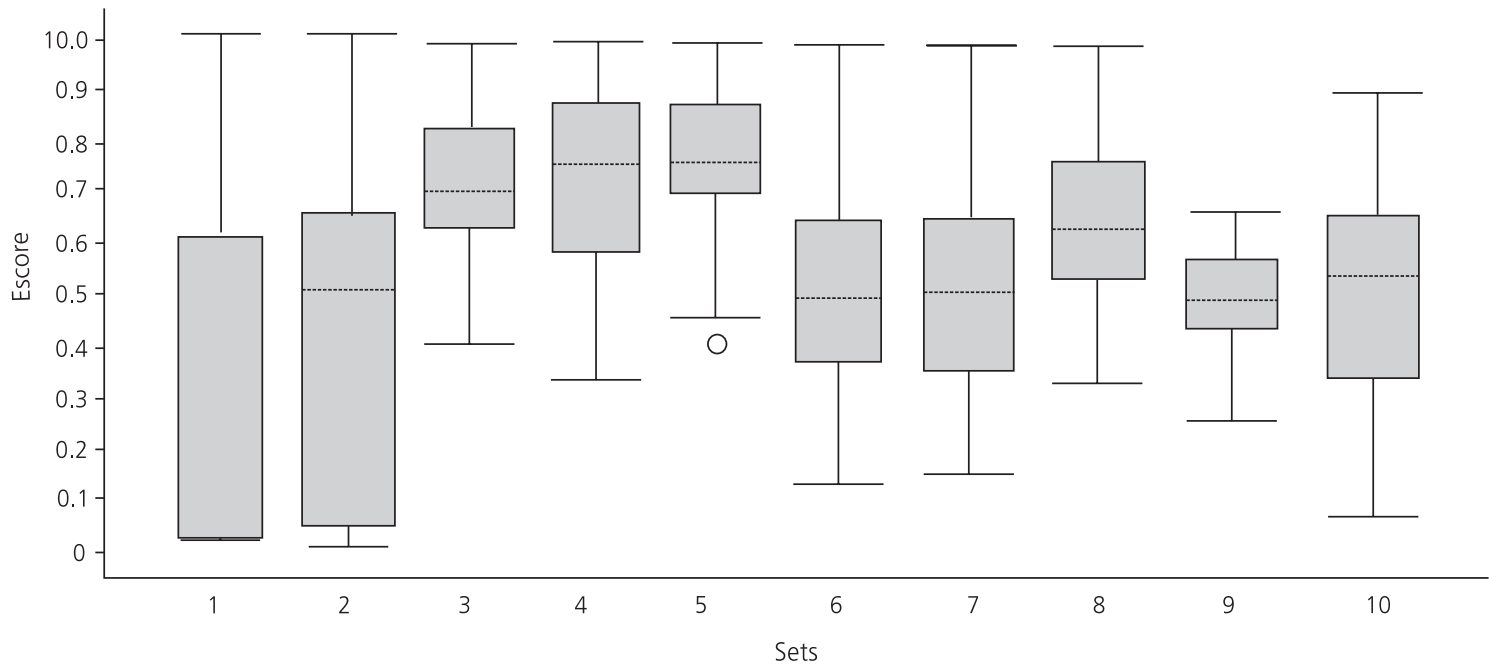

Figure 1. Scatter box plot showing the scores of each set of items used for assessing the Breastfeeding-Friendly Primary Care Initiative. Rio de Janeiro (RJ), Brazil, 2008. 
392 | RVVF RITO et al.

Table 2. Mean final score of the Breastfeeding-Friendly Primary Care Initiative implementation by region and by primary care unit care model. Rio de Janeiro (RJ), Brazil, 2008.

\begin{tabular}{lccc}
\hline Variables & $N^{\circ}$ primary care units & Mean & $95 \%$ confidence interval \\
\hline Regions & 4 & & $4.160-4.427$ \\
1 & 7 & 4.294 & $4.897-6.045$ \\
2 & 16 & 5.471 & $4.526-5.821$ \\
3 & 4 & 5.174 & $4.601-7.308$ \\
4 & 25 & 5.954 & $5.203-6.322$ \\
5 & & 5.762 & \\
Care Model & & & $4.998-5.860$ \\
PCU & 28 & 5.429 & $4.947-5.985$ \\
FHS & 28 & 5.466 & \\
\hline
\end{tabular}

Note: PCU: Primary Care Units with traditional care models; FHS: Family Health Strategy (healthcare clinics run by the FHS/Community Health Agents Program).

The following sets had the best scores, ranging from 0.706 to 0.763 : set 3 (informing mothers of their breastfeeding rights, the advantages of breastfeeding, and related recommendations); set 4 (supporting and boosting mothers' confidence); and set 5 , (practitioners' and pregnant women's knowledge of procedures that encourage breastfeeding during the neonatal period).

Figure 1 shows the degrees of implementation of the ten sets by the study units. The degree of implementation of sets 3, 5, 8, and 9 by all the units was similar, while that of sets 4,6 , 7 , and 10 varied to some extent, and that of sets 1 and 2 varied mostly.

Comparison of the five regions showed that region 1 had the worst degree of $\mathrm{BFPCl}$ implementation, but its final score did not differ significantly from the mean score of the other four study regions. When the units were grouped by care model, the mean final scores were also similar (Table 2).

\section{DISCUSSION}

The degree of $\mathrm{BFPCl}$ implementation in the municipality of Rio de Janeiro was intermediate, and region 1 obtained the worst score. These findings reflect the fact that region 1 had invested the least in professional training for promoting breastfeeding and for $\mathrm{BFPCI}$ implementation, as shown by SMS-RJ's Annual Report on Actions Promoting, Protecting and Supporting Breastfeeding of 2008, kindly provided by their Child Healthcare Program Coordination.

Less than one third of the study units had written breastfeeding guidelines, despite this having been determined by the Ministry of Health. This procedure is essential for building an institutional legacy and for actual breastfeeding ${ }^{15}$. These findings confirm those reported by Toma \& Monteiro ${ }^{16}$ when they used Baby-Friendly Hospital Initiative criteria to assess breastfeeding promotion in 45 maternity hospital clinics in the municipality of São Paulo. These criteria also require the availability of printed copies of the breastfeeding guidelines but the authors noted difficulties in compliance with this step, as these printed copies were only available to the healthcare staff in a minority of public hospitals and in no private hospitals.

Despite the efforts of the SMS-RJ managers to provide training courses, set 2 , which includes staff training, obtained the second lowest mean score. This poor performance may be explained by the number of practitioners who still required training, since Rio de Janeiro - Brazil's second largest metropolis - has numerous primary care units employing thousands of practitioners. 
In other words, many courses are necessary to ensure high training penetration rate.

The small number of trained professionals corroborates the findings of the first assessment of compliance with the Ten Steps for Successful Breastfeeding at Baby-friendly Hospitals done in Brazil ${ }^{17}$. On that occasion, the implementation of training courses was also small, confirming the need to assign high priority to training to improve advice quality and effective support for pregnant women and new mothers. However, the existence of a practitioner training policy that blends the precepts of critical and reflective education, ongoing healthcare education, and problematization ${ }^{17}$, resulting in appropriate support for mothers during the prenatal, natal, and postnatal periods, is an important requirement for increasing breastfeeding prevalence ${ }^{11}$. Caldeira et $a l .{ }^{18}$ noted that the family health team training proposed by the BFPCI proved to be an effective, inexpensive strategy for increasing practitioner awareness, helping them to provide more homogeneous information and better support to mothers with breastfeeding difficulties.

The sets with intermediate degrees of implementation, which consequently warrant more attention during the training sessions, were: showing women how to breastfeed and maintain milk production; providing guidance on appropriate contraception while breastfeeding and on the risks associated with the use of artificial nipples; and strengthening the social support network for breastfeeding. Recent studies reiterate the need for investments in this area, especially practitioner training. When studying infant growth, Jaldin et al. ${ }^{2}$ pointed out the importance of using the right breastfeeding techniques, emptying the breast completely at each feed, and explaining that the milk produced at the end of each feed is higher in fats and energy, resulting in satiety and greater weight gain; they also stress that constant support for mothers during childcare is crucial for boosting mothers' self-esteem, making them believe in their ability to breastfeed. Meanwhile, Roig et al. ${ }^{19}$ warn of the need to disseminate knowledge about the use of bottles and pacifiers and their association with weaning in the first six months of life.

In general, knowledge about the advantages, rights, and recommendations on exclusive and non-exclusive breastfeeding (set 3 ) was well absorbed by the study practitioners and mothers. Similarly, knowledge about breastfeeding during the first hour of life and about the importance of room sharing and breastfeeding on demand (set 5) was satisfactory. Furthermore, set 4 (which addresses the reception given to pregnant and breastfeeding women and the boosting of their confidence by listening to their breastfeedingrelated concerns, experiences, and doubts) was much better implemented than nearly all other sets (except for set 5).

In general lines, our findings converge with those of Cruz et al. ${ }^{20}$ with respect to the guidelines best incorporated by primary care practitioners.

Cruz et al. ${ }^{20}$ investigated what breastfeedingrelated advice women with children aged two years or less had received in primary care units and found that more than $70 \%$ had been advised to start breastfeeding within the first hour of life. Additionally, they were informed about the advantages of exclusive breastfeeding for six months and about the importance of breastfeeding on demand and suction for milk production. Smaller proportions (between 59\% and $68 \%$ ) were taught how to manually express milk and position themselves and the child; advised to breastfeed until the child was two years old or older; and informed of the harm caused by pacifiers and bottles and of breastfeeding difficulties.

However, our findings differ from those of Cruz et al. ${ }^{20}$ regarding the difference between primary care units that follow a traditional care model and family health units: while our study found no statistically significant differences between the units grouped by care model, Cruz et $a l .{ }^{20}$ found that women seen at family health 
units were more likely to have received all the breastfeeding advice than those seen at units that follow the traditional model. The different degrees of practitioner training found by the two studies may explain this discrepancy. Cruz et al. ${ }^{20}$ hypothesized that this difference by care model stemmed from the more recent training given to practitioners from family health units. However, at the time of the present study, training activities associated with $\mathrm{BFPCI}$ implementation had been given to practitioners in all healthcare units, regardless of care model.

In terms of internal validity, the present study assessed the units with the same tools as those used by experts to award BFPHU titles. During the final phase of the fieldwork, one of the units was excluded because of urban violence and it could not be replaced. A second unit was closed but we decided not to replace it because the sample size could accommodate these two losses.

As mentioned earlier, number of items per set varied, as did the scores attributed to each item. However, all sets were given equal weight in the final score to reflect the BFPHU title-awarding process, where all ten steps have the same weight.

In terms of external validity, the assessment method used by the present study may be used for assessing actions that promote, protect, and support breastfeeding in primary care units of other municipalities that strive to follow the study sets.

In summary, the primary care units of Rio de Janeiro were able to implement many practices that promote breastfeeding, encouraging practitioners to promote them too. On the other hand, managers need to review the resources available at the central, regional, and local levels, such as the creation and dissemination of breastfeeding guidelines and routines, and professional training.

The present study demonstrated the importance of developing a tool for assessing the implementation of policies that promote breastfeeding, such as the BFPCl; a tool that does not rely only on the number of units awarded the $\mathrm{BFPCI}$ title and that allows the identification of aspects critical for improving this implementation. In addition to assessing healthcare as a whole, at the municipal or regional levels, the proposed tool allows each primary care unit manager to examine the specific reality of his unit and perform peer reviews of the implementation process at the local level.

The consolidation of a breastfeeding culture depends on numerous factors. To improve the knowledge about this process, this study proposes an innovative tool capable of better identifying the dynamics of breastfeeding promotion done by the healthcare sector.

\section{ACKNOWLEDGMENTS}

The Authors would like to thank the Municipal Department of Health of Rio de Janeiro for the support given to this study, and Fabio da Silva Gomes for his collaboration in data analysis.

\section{CONTRIBUTORS}

RVVF RITO and IRR CASTRO contributed to the concept and design of the study, data collection, analysis, and interpretation, and manuscript writing and final review. AJB TRAJANO and MASM GOMES contributed to project conception and manuscript. RTI BERNAL contributed to sampling design, data analysis, and to the manuscript.

\section{REFERENCES}

1. Brasil. Ministério da Saúde. Secretária de Atenção à Saúde. Saúde da criança. Nutrição infantil: aleitamento materno e alimentação complementar. Brasília: MS; 2009.

2. Jaldin MGM, Pinheiro FS, Santos AM, Muniz NC. Crescimento infantil comparado com as referências NCHS e o padrão WHO/2006. Rev Nutr. 2013; 26(1):17-26. doi: 10.1590/S1415-527320130001 00002 .

3. Dias MCAP, Freire LMS, Franceschini SCC. Recomendações para alimentação complementar de crianças 
menores de dois anos. Rev Nutr. 2010; 23(3):475-86. doi: 10.1590/S1415-52732010000300015.

4. Kac G, Benício MHDA, Velásquez-Meléndez G, Valente JG, Struchiner CJ. Breast feeding and postpartum weight retention in a cohort of Brazilian women. Am J Clin Nutr. 2004; 79(3):487-93.

5. Rea MF. Os benefícios da amamentação para a mulher. J Pediatr. 2004; 80(Supl 5):142-6. doi: 10.15 90/S0021-75572004000700005.

6. Brasil. Ministério da Saúde. Pesquisa nacional de demografia e saúde da criança e da mulher: PNDS 2006: dimensões do processo reprodutivo e da saúde da criança. Brasília: MS; 2008.

7. Campagnolo PDB, Louzada MLC, Silveira EL, Vitolo MR. Práticas alimentares no primeiro ano de vida e fatores associados em amostra representativa da cidade de Porto Alegre, Rio Grande do Sul. Rev Nutr. 2012; 25(4):431-9. doi: 10.1590/S1415-52 732012000400001.

8. Rea MF. Reflexões sobre a amamentação no Brasil: de como passamos a 10 meses de duração. Cad Saúde Pública. 2003; 19(Supl 1):37-45. doi: 10.15 90/S0102-311X2003000700005.

9. Almeida JAG, Novak FR. Amamentação: um híbrido natureza-cultura. J Pediatr. 2004; 80(5 Supl):119-25. doi: 10.1590/SO104-11691998000300009.

10. de Oliveira MIC, Camacho LAB. Impacto das Unidades Básicas de Saúde na duração do aleitamento materno exclusivo. Rev Bras Epidemiol. 2002; 5(1): 41-51. doi: 10.1590/S1415-790X2002000100 006.

11. Ramos CV, Almeida JAG, Pereira LMR, Pereira TG. A iniciativa Hospital Amigo da Criança sob a ótica dos atores sociais que a vivenciam em Teresina, Piauí. Rev Nutr. 2010; 23(6):1019-30. doi: 10.15 90/S1415-52732010000600008.

12. de Oliveira MIC, Camacho LAB, Souza IEO. Promoção, proteção e apoio à amamentação na atenção primária à saúde no Estado do Rio de Janeiro, Brasil: uma política de saúde pública baseada em evidência. Cad Saúde Pública. 2005; 21(6):1901-10. doi: 10.1590/SO102-311X20050 00600040 .
13. Rio de Janeiro. Resolução SES n².673, de 2 de março de 2005. Implanta a Iniciativa Unidade Básica Amiga da Amamentação no Estado do Rio de Janeiro e dá outras providências. Diário Oficial do Estado do Rio de Janeiro. 2005; 14 mar.

14. Silva NN. Amostragem probabilística. $2^{a}$ ed. São Paulo: Edusp; 2000.

15. Dubeux LS, Frias PG, Vidal AS, Santos DM. Incentivo ao aleitamento materno: uma avaliação das equipes de saúde da família do município de Olinda, Pernambuco. Rev Bras Saúde Mater Infant. 2004; 4(4):399-404. doi: 10.1590/\$1519-3829200400 0400009.

16. Toma TS, Monteiro CA. Avaliação da promoção do aleitamento materno nas maternidades públicas e privadas do município de São Paulo. Rev Saúde Pública. 2001; 35(5):409-14. doi: 10.1590/S0034-89 102001000500001.

17. Araújo LDS. A construção de um novo olhar no ensino de aleitamento materno: uma contribuição da educação crítico-reflexiva [tese]. São Paulo: Universidade de São Paulo; 2005.

18. Caldeira AP, Fagundes GC, Aguiar GN. Intervenção educacional em equipes do Programa de Saúde da Família para promoção da amamentação. Rev Saúde Pública. 2008; 42(6):1027-33. doi: 10.15 90/S0034-89102008005000057.

19. Roig AO, Martínez MR, García JC, Hoyos SP, Navidad GL, Alvarez JCF, et al. Fatores associados ao abandono do aleitamento materno durante os primeiros seis meses de vida. Rev Latino-Am Enfermagem. 2010; 18(3):373-80. doi: 10.1590/S0104-1 1692010000300012.

20. Cruz SH, Germano JA, Tomasi E, Facchini LA, Piccini RX, Thumé E. Orientações sobre amamentação: a vantagem do Programa de Saúde da Família em municípios gaúchos com mais de 100.000 habitantes no âmbito do PROESF. Rev Bras Epidemiol. 2010; 13(2):259-67. doi: 10.1590/S1415-790X20 10000200008 .
Received on: 11/7/2012 Final version on: $25 / 3 / 2013$ Approved on: 29/4/2013 
